\title{
Histological findings in human brucellosis
}

\author{
A. C. HUNT AND P. W. BOTHWELL \\ From the Departments of Pathology and Public Health, University of Bristol
}

SYNOPSIS The histological findings in 14 cases of brucellosis are described. Unusual findings include the occurrence of brucellosis in a patient with Hodgkin's disease and in another with lymphosarcoma. A patient with hepatic cirrhosis apparently due to brucellosis is included in the series.

Human brucellosis is fatal in $1 \%$ to $2 \%$ of recognized cases, and reports of 45 deaths from this disease are recorded in the British literature although in only a few are the pathological findings described. A further series of 27 deaths ascribed to brucellosis occurring in the British Isles between 1949 and 1960 has already been collected and studied (Bothwell, 1963). Histological material was available in 10 of these cases. This material, together with biopsy specimens from four other non-fatal proven cases, are reviewed here. The necropsies were all performed by different pathologists, and histological sections were not available from all organs in every case, but sufficient lesions were found to make publication of some of the histological findings worth while.

\section{THE LIVER}

The liver is commonly involved in both acute and chronic brucellosis. Unfortunately no large series is available to indicate the frequency of liver lesions that might be expected in liver biopsy material. Spink, Hoffbauer, Walker, and Green (1949) examined liver biopsies from 11 patients with brucellosis, and found granulomata in all. In none of their cases were the results of tests of liver function more than slightly abnormal. They point out that the hepatic lesions are not specific, and histologically cannot be distinguished from those of sarcoidosis, a view with which we agree.

More severe liver involvement with hepatosplenomegaly and jaundice has also been reported (Chaikin and Schwimmer, 1943; Young, 1947; Rossmiller and Ensign, 1948; Nushan and Bailey, 1953). In a large series of cases of brucellosis, Cantaloube (1911) demonstrated clinically an enlarged liver in $10 \%$. As well as granulomatous lesions, centrilobular necrosis (Hardy, Jordan, Borts, and Hardy, 1931), focal necrosis (McCullough and Eisele, 1951), and extensive destruction of liver parenchyma (Wohlwill, 1932) have been described.

A number of cases of hepatic cirrhosis claimed to be due to brucellosis are on record (Schittenhelm, 1932; Rothenberg, 1933; Pedro Pons, Bacardi Noquera, and Alvarez Zamora, 1945; Spink et al., 1949). Most of these were patients with established cirrhosis who had positive bacteriological or serological evidence of brucella infection. The causative role of this infection in the production of the cirrhosis was only presumptive.

In 1951, McCullough and Eisele described a man with bacteriologically proven brucella infection in whom a liver biopsy showed extensive focal necrosis, cellular infiltration, and typical brucella granuloma. A second liver biopsy two years later showed a welldeveloped portal type of cirrhosis.

CASE REPORTS Sections of liver were available in nine cases, six from necropsy material and three from liver biopsies. The liver was normal in three of the six necropsies, but all three biopsies were abnormal, two showing granulomatous lesions and one showing cirrhosis.

Active inflammatory lesions In all the five cases showing active inflammation, focal granulomas were seen, although sometimes a prolonged search of several sections was necessary before one was found (Figs. 1 and 2). The granulomas were made up of epithelioid macrophages, lymphocytes, plasma cells, and a few polymorphonuclear leucocytes. Multinucleate giant cells were present in most, but not all, granulomas. When present they varied in size from cells with a few nuclei to cells with $\mathbf{4 0}$ or $\mathbf{5 0}$ nuclei.

Besides the granulomata, all the sections showed more or less infiltration of the sinusoids with lymphocytes, plasma cells, and occasional polymorphs (Fig. 3). Occasionally multinucleate giant cells were present in the sinusoids quite distinct from the granulomatous lesion. In one case there was patchy necrosis of liver cells.

Cirrhosis A girl of 4 years of age had two attacks of 


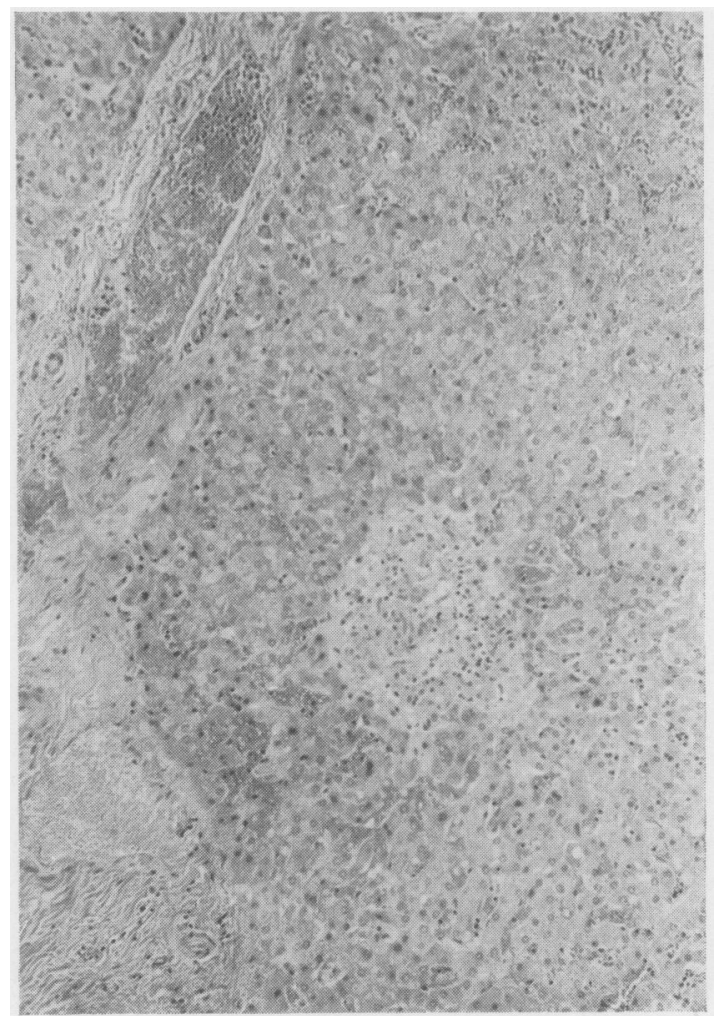

FIG. 1.

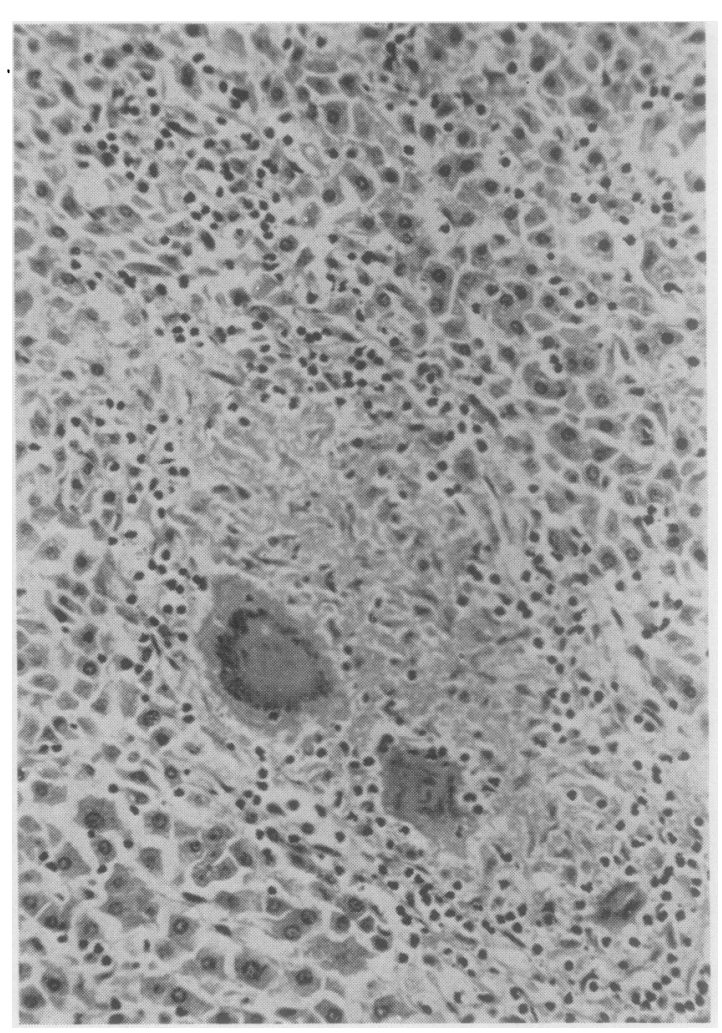

FIG. 2.

FIG. 1. Brucella granuloma in liver. Haematoxylin and eosin $\times 100$.

FIG. 2. Hepatic granuloma with prominent giant cells. Haematoxylin and eosin $\times 200$.

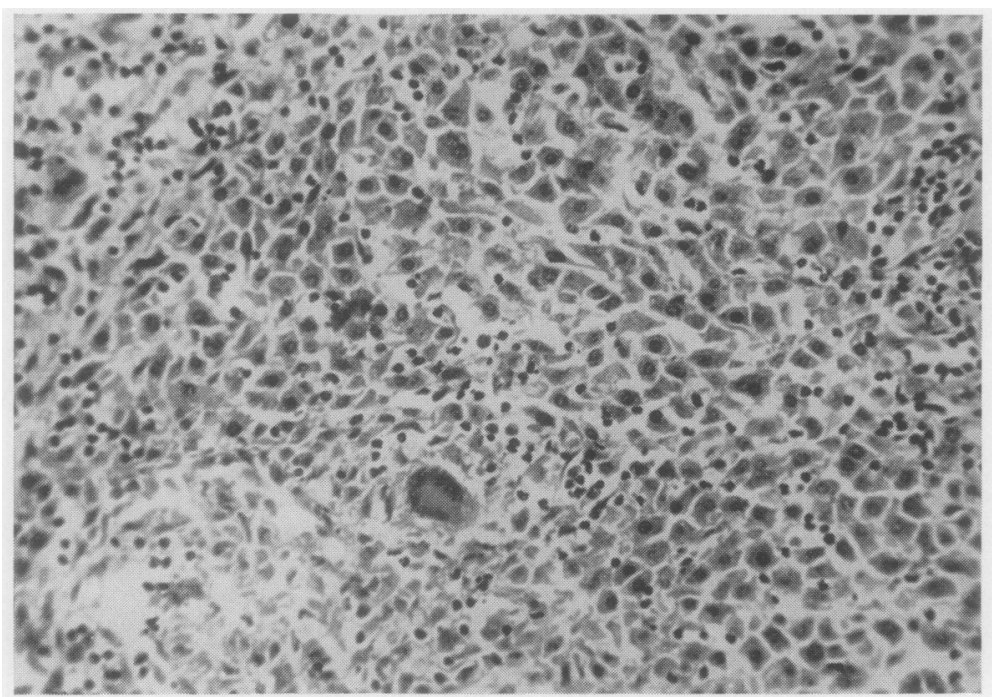

FIG. 3. Diffuse cellular infiltration of liver. Haematoxylin and eosin $\times 150$. 


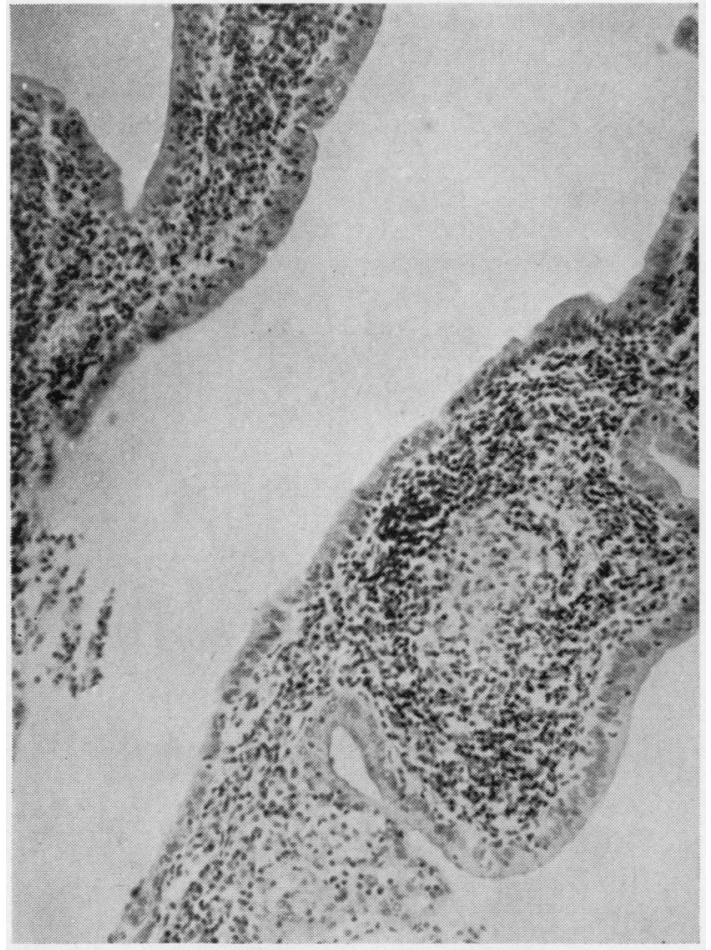

FIG. 4. Cellular infiltration of gall bladder wall. Haematoxylin and eosin $\times 80$.

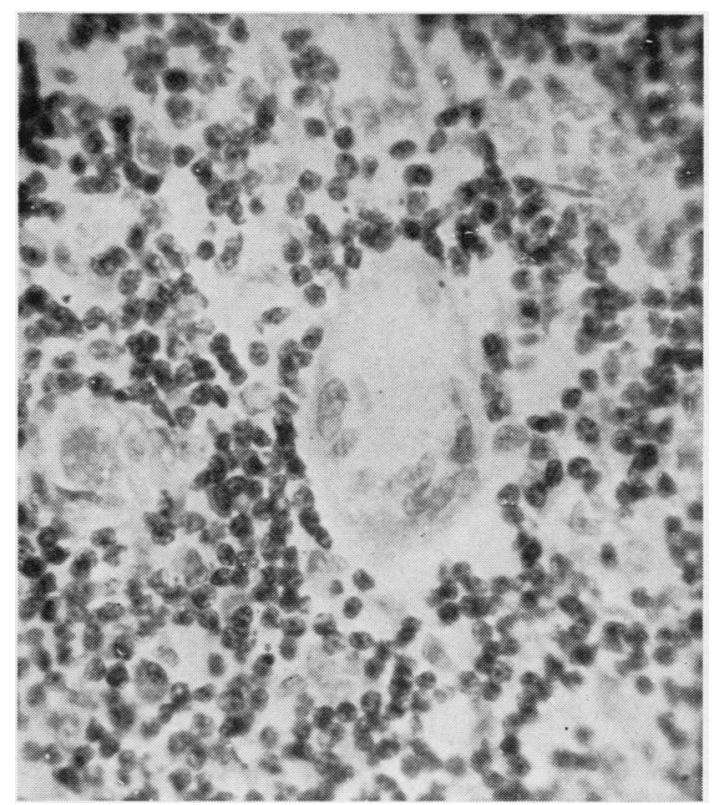

FIG. 5. Giant cells in gall bladder wall. Haematoxylin and eosin $\times 250$. fever and jaundice, and in the second was found to have a titre of $1: 1,000$ to Brucella abortus, and a positive brucellin test. Three months later she developed ascites. At the age of 9, following repeated haematemeses, a portocaval anastomosis was performed. Biopsy of the liver at operation showed a typical portal type of cirrhosis with no specific indication of brucellosis. Although it is impossible to prove that the cirrhosis was due to brucellosis, it must be a very strong possibility.

\section{THE GALL BLADDER}

Several examples of involvement of the gall bladder in brucellosis have been reported (Simpson and Bowers, 1929; Leavell and Amoss, 1931; Mettier and Kerr, 1934). In only one is there any description of the pathological changes (Leavell and Amoss, 1931). In this case the gall bladder wall showed a granulomatous inflammation, and Brucella melitensis was cultured from it.

CASE REPORT A 58-year-old woman developed a fever and a titre of $1: 5,000$ against Brucella abortus was discovered. Fourteen months later fever recurred and she suffered bouts of pain in the right hypochondrium. The Brucella abortus antibody titre was $1: 1,200$. Her gall bladder was removed and a large laminated stone was found in it. The gall bladder wall was thickened and histologically it was found to be heavily infiltrated with lymphocytes and plasma cells. In this infiltration there were focal collections of epitheloid cells (Fig. 4). There were also similar cells scattered in the infiltrate and near the serosa a few giant cells were found (Fig. 5).

\section{THE TESTICLE}

Orchitis and epididymitis occur as a complication of brucellosis in man in from $4 \%$ to $20 \%$ of cases (Hardy, 1928; Wainwright, 1929). There is only one description of the pathological changes in the testis in the literature (Rothenberg, 1933) and this merely describes one case as showing 'active interstitial orchitis and scattered areas of fibroid atrophy'.

CASE REPORT A 44-year-old farmer gave a four-week history of fever and painful swelling of the right testicle. He died from a massive pulmonary embolism following a femoral venous thrombosis. Three days before death his Brucella abortus antibody titre was $1: 250$. This level is considered to be diagnostic of active disease. Wilson and Miles (1964) have suggested $1: 80$ and Spink (1956) $1: 160$ as diagnostic titres.

Histologically the whole of the interstitial tissue of the right testicle was infiltrated by chronic inflammatory cells, of which the majority were lymphocytes and the rest were plasma cells and a few were macrophages. The tubules were widely separated by the cellular exudate, and many were being infiltrated by it. In places the tubules were so disorganized that an appearance of focal granulomata was produced (Fig. 6). There were, however, 


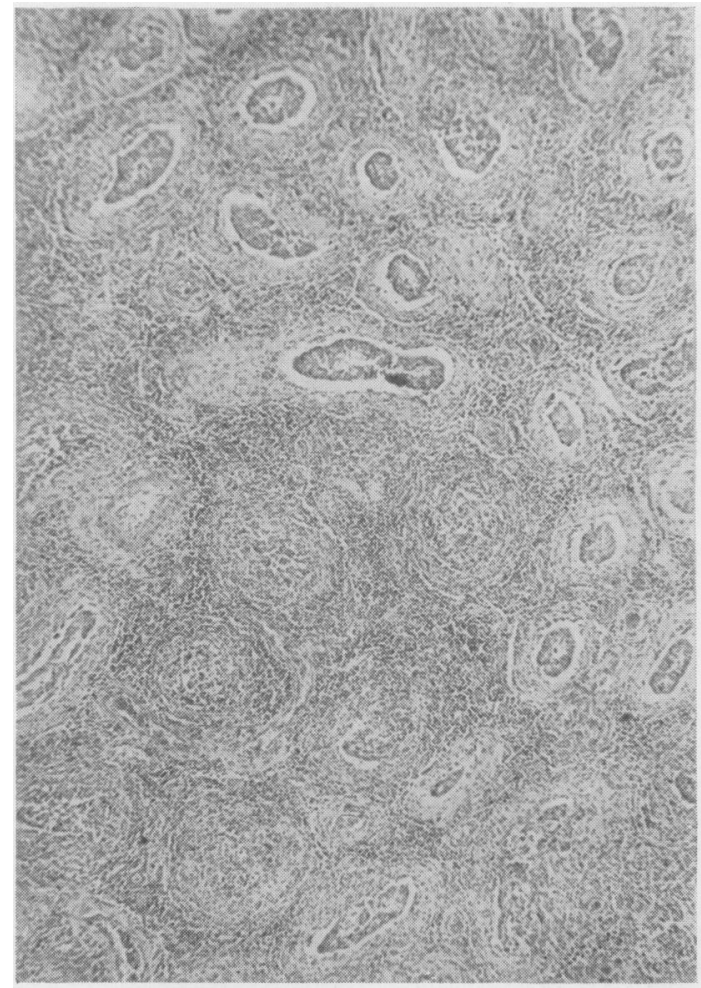

FIG. 6. Inflammatory changes in testicle. Some of the tubules are disorganized and give a false impression of granuloma formation. Haematoxylin and eosin $\times 120$.

no cell collections that could confidently be diagnosed as true granulomata, no giant cells were present, and the appearances were non-specific. The epididymis showed similar but less severe cellular infiltration.

\section{THE HEART}

The commonest cardiac involvement in brucellosis is in the form of an endocarditis. No lesions of this nature occurred in our series. An excellent review of this aspect of the subject is that of Hart, Morgan, and Lacey (1951). Infective vegetations occur on the aortic or mitral valves, usually when these are the seat of some predisposing abnormality such as rheumatic scarring or congenital abnormality.

Recently the interesting suggestion has been put forward by Peery (1958) and by Konwaler, Carpenter, and Ohno (1960) that brucellosis itself may be responsible for a chronic valvular change akin to that occurring in rheumatic disease, although the evidence that this may be so is not at all strong. The main basis for the suggestion is evidence of a marked prevalence of dermal sensitivity to brucellergen in one series of patients with chronic cardiovascular disease (Carpenter and Leik, 1956).

Granulomatous lesions have been described in the myocardium in two cases of brucella endocarditis (Call, Baggenstoss, and Merritt, 1944), which were felt to have certain similarities to rheumatic fever. Experimentally Konwaler and his colleagues produced focal lesions in the myocardium of guinea-pigs by infecting them with Brucella suis, and some of these lesions resembled Aschoff bodies, even if they could not be unequivocally described as such. True Aschoff bodies have not been reported in human brucellosis.

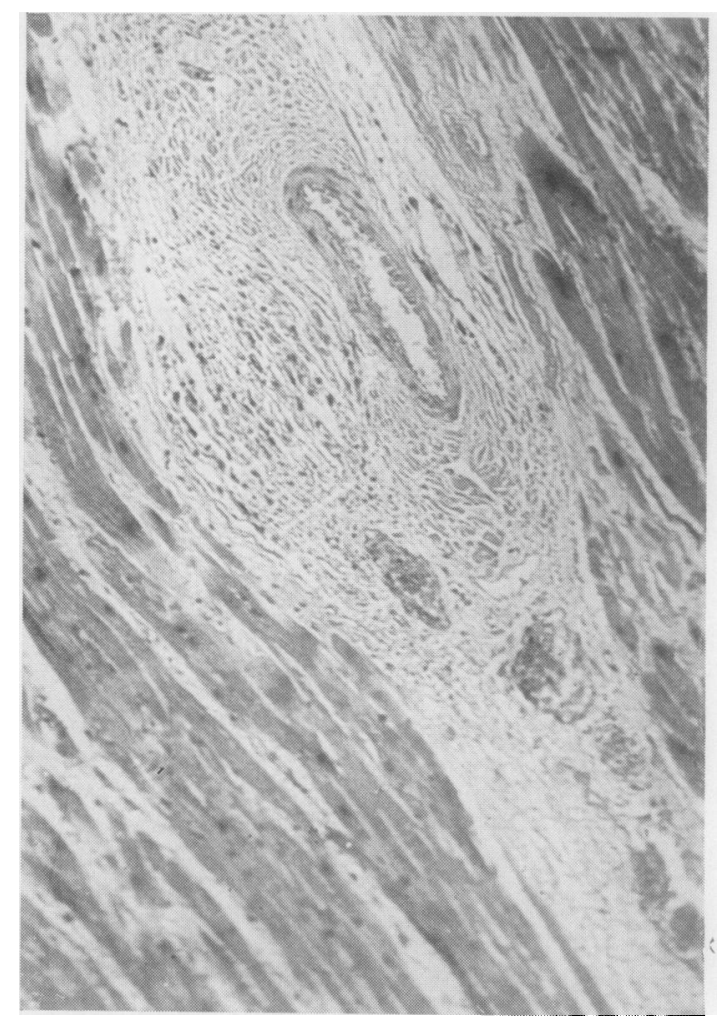

FIG. 7. Cellular aggregation in left ventricular myocardium of patient with brucellosis. Haematoxylin and eosin $\times 120$.

CASE REPORT No example of Brucella endocarditis was seen in this series, but in one case of undoubted brucellosis a lesion very like an Aschoff body was seen in the myocardium. This was in a young man with a history of fever for two and a half months who died from a massive pulmonary embolism. During the illness he had a titre of 1:640 against Brucella abortus, and at post-mortem examination typical brucella lesions were found in the liver and spleen. 
The lesion in the heart was a single small cellular aggregate about half a millimetre long beside an artery deep in the myocardium of the left ventricle (Fig. 7). It was composed of cells with abundant basophilic cytoplasm, and with large rather twisted and irregular nuclei resembling Anitschkow myocytes.

THE SPLEEN

Enlargement of the spleen is a common finding in patients suffering from brucellosis. Descriptions of the pathological changes in this organ include giant cells and increased numbers of macrophages in the sinusoids (Rothenberg, 1933; Rabson, 1939) and focal granulomata (Wohlwill, 1932). The granulomata resemble brucella granuloma in the liver and are often most clear and numerous in the Malpighian bodies. Besides these specific changes, the spleen is said usually to show lymphoid hyperplasia.

CASE REPORT Material was available in two cases. In both there was a diffuse increase in the macrophages in the pulp, and both showed focal granulomata, one very many more than the other. In the former there was one

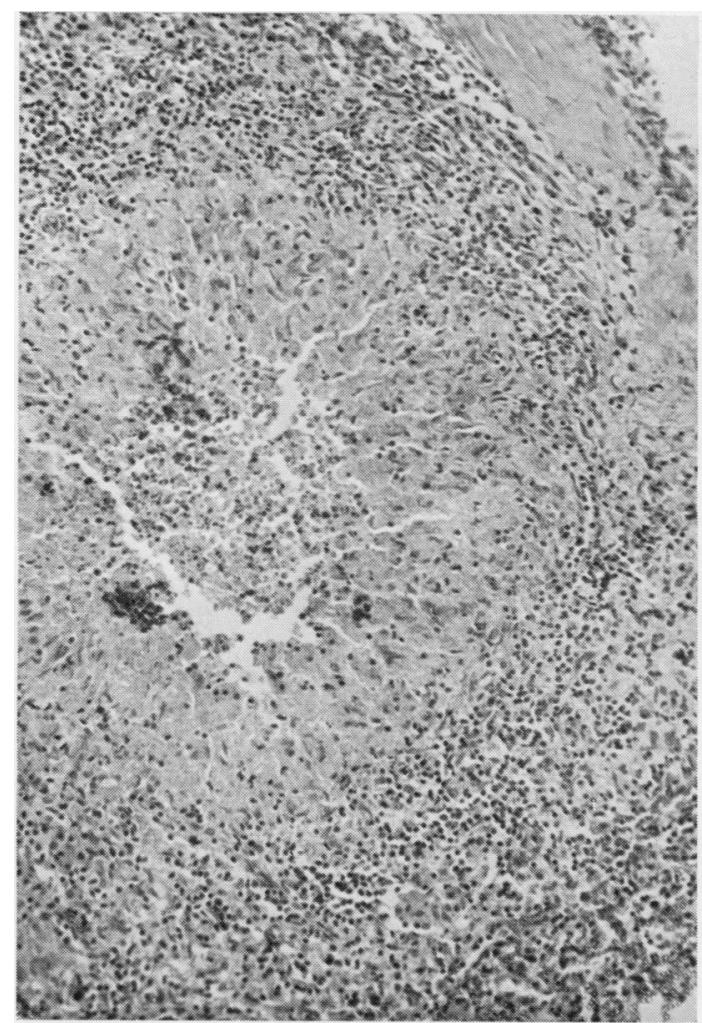

FIG. 8. Spleen. Central necrosis in brucella granuloma. Haematoxylin and eosin $\times 100$. granuloma which showed central necrosis (Fig. 8). Central necrosis has not hitherto been recorded in the granulomata of human brucellosis. The fact that it may occur, even if rarely, is of obvious importance, as most histopathologists would be loath to diagnose brucellosis from a granuloma showing such necrosis.

None of the granulomas in these two spleens contained any giant cells.

\section{ASSOCIATION WITH HODGKIN'S DISEASE}

In 1939 Parsons and Poston described four cases of human brucellosis in which the necropsy findings were typical of Hodgkin's disease. In 1940 Wise and Poston described a further 14 cases in which there was coexistent Hodgkin's disease and brucellosis, and in 1941 Forbus and Gunter described four more similar cases. All this work came from the same centre, and other workers failed to find any more cases. It was of interest to find, therefore, that in one of our fatal cases in which brucellosis was demonstrated bacteriologically, the findings at necropsy were of Hodgkin's disease, and that in another patient with generalized lymphosarcoma a titre of $1: 250$ against brucella was demonstrated in life. A generalized poverty of immunological mechanism has been demonstrated in patients with Hodgkin's disease (Dubin, 1947). It seems reasonable to suppose that brucellosis may be more likely to occur in patients with a generalized disease of the reticuloendothelial system than in normal people. It is possible that brucella infection is occasionally responsible for deterioration and death in Hodgkin's disease without its presence being suspected. Owing to the concomitant suppression of a normal antibody response, anti-brucella titres may be of no value, and culture of the organism may be necessary to make a diagnosis. The importance of making such a diagnosis where a treatable disease of this nature is involved is clear, even in the presence of an underlying disease that ultimately will prove fatal. It might be suggested that brucellosis itself may produce alterations in the lymph nodes that may resemble Hodgkin's disease. The changes described in the literature in the lymph nodes of brucellosis include infiltration of the nodes with mononuclear cells (Sprunt and McBryde, 1936), 'reticulo-endothelial hyperplasia' (Sharp, 1934), and the appearance of the typical focal epithelioid cell granulomata (Wohlwill, 1932; Rössle, 1933). Unfortunately in none of our cases, apart from the two with Hodgkin's disease and lymphosarcoma, were the lymph nodes examined. It seems most unlikely that an infective process could produce the typical disorganization of the architecture and the cytological appearance of Hodgkin's disease, and in our case of lymphosarcoma besides the lymph node changes there was 
lymphosarcomatous infiltration of the liver quite unlike the liver lesions of brucellosis.

\section{DISCUSSION}

The longest review of brucellosis in the literature is that of Dalrymple-Champneys (1960) who analysed 1,483 cases, including 24 fatalities.

Among Dalrymple-Champneys's cases were four with endocarditis and five with significant hepatic involvement (of which one had cirrhosis). Four cases had haemorrhagic conditions (two intestinal, one epistaxis, one haematuria). However, he considered that in his series brucellosis alone was rarely the cause of death. Three of the cases with cardiac involvement which he reviewed have been described in more detail by Rennie and Young (1936), by Hart et al. (1951), and by Grant and Stote (1953).

In eight cases described in Scotland (Beattie, Smith, and Tulloch, 1935; Smith, 1951) death was caused by cirrhosis of the liver, haemorrhagic conditions, pancreatitis, heart failure, tuberculous peritonitis, and disseminated sclerosis.

Another fatal case was described by Barrett and Rickards (1953), in which death was due to pulmonary embolism following thrombophlebitis of the left calf.

The most commonly reported clinical complications of brucellosis are neuropsychiatric disorders and bone or joint involvement, but they do not appear to be the lethal factors.

Histological study of material from cases of human brucellosis at necropsy in Britain has not been extensive. Brucellosis can affect any organ, but more information from necropsy examinations is required to build up a complete picture of the distribution of pathological changes in the disease.

Our thanks are due to the fourteen pathologists who allowed us access to their post-mortem reports and histological sections. One of us (P.W.B.) is indebted to the A.R.C. for a personal grant for expenses in connexion with this study.

\section{REFERENCES}

Barrett, G. M., and Rickards, A. G. (1953). Quart. J. Med., 22, 23. Beattie, C. P., Smith, J., and Tulloch, W. J. (1935). Lancet, 1, 1427. Bothwell, R. W. (1963). Brit. med. J., 1, 1481.

Call, J. D., Baggenstoss, A. H., and Merritt, W. A. (1944). Amer. J.ত clin. Path., 14, 508.

Cantaloube, P. (1911). La Fièvre de Malte en France, bj' A. Maloine, Paris.

Carpenter, C. M., and Leik, D. W. (1956). Paper presented to Amer. $\overparen{(\mathbb{D}}$ Soc. Trop. and Med. Hyg., 1st November, New Orleans, La.

Chaikin, N. W., and Schwimmer, D. (1943). Rev. Gastroent., 10, 130 ు) Dalrymple-Champneys, W. (1960). Brucella Infection and Undulant Fever in Man. Oxford University Press, London.

Dubin, I. N. (1947). Ann. intern. Med., 27, 898.

Forbus, W. D., and Gunter, J. U. (1941). Sth. med. J. (Bgham, Ala), 34, 376.

Grant, G. H., and Stote, C. L. (1953). Brit. med. J., 1, 914.

Hardy, A. V. (1928). J. lowa St. med. Soc., 18, 387. ordan, C. F., Borts, I. H., and Hardy, G. C. (1931). Nat. Inst. i Hith Bull., 158 ,

Hart, F. D., Morgan, A., and Lacey, B. (1951). Brit. med. J., 1, 1048. $\omega$ Konwaler, B. E., Carpenter, C. M., and Ohno, S. (1960). Amer. OS Heart J., 59, 101.

Leavell, H. R., and Amoss, H. L. (1931). Amer. J. med. Sci., 181, 96. McCullough, N. B., and Eisele, C. W. (1951). Arch. intern. Med., 88, 793.

Mettier, S. R., and Kerr, W. J. (1934). Ibid., 54, 702.

Nushan, H., and Bailey, A. A. (1953). Ann. intern. Med., 39, 915.

Parsons, P. B., and Poston, M. A. (1939). Sth. med. J. (Bgham, Ala), 32, 7.

Pedro Pons, A., Bacardi Noguera, R., and Alvarez Zamora, R. (1945). Med clin. (Barcelona), 5, 15.

Peery, T. M. (1958). J. Amer. med. Ass., 166, 1123,

Rabson, S. M. (1939). Amer. J. clin. Path., 9, 604.

Rennie, J. K., and Young, C. J. (1936). Brit. med. J., 1, 412

Rössle, R. (1933). Münch. med. Wschr., 80, 5.

Rossmiller, H. R., and Ensign, W. G. (1948). Cleveland Clin. Ouart. $15,184$.

Rothenberg, R. C. (1933). Ann. intern. Med., 6, 1275.

Schittenhelm, A. (1932). Klin. Wschr., 11, 905.

Sharp. W. B. (1934). Arch. Path., 18, 72.

Simpson, W. M., and Bowers, L. G. (1929). Amer. J. Surg., 7, 597.

Smith, J. (1951). Hlth Bull. (Edinb.), 9, 57.

Spink, W. W. (1956). Semin. int. med. Res. Div. Sharp and Dohme, 5 त् (2), 15

—, Hoff bauer, F. W., Walker, W. W., and Green, R. A. (1949). J. Lab. clin. Med., 34, 40.

Sprunt, D. H., and McBryde, A. (1936). Arch. Path., 21, 217.

Wainwright, C. W. (1929). Bull. Johns Hopk. Hosp., 45, 133.

Wilson, G. S., and Miles, A. A. (1964). Topley and Wilson's Principles of Bacteriology and Immunity, 5th ed., p. 2039. E. Arnold, London.

Wise, N. B., and Poston, M. A. (1940). J. Amer. med. Ass., 115, 1976. Wohlwill, F. (1932). Virchows Arch. path. Anat., 286, 141.

Young, J. D. (1947). Memphis med. J., 22, 168. 